\title{
Presentism Remains
}

\author{
Jonathan Tallant ${ }^{1}$
}

Received: 1 March 2017/Accepted: 20 November 2017/Published online: 18 December 2017

(C) The Author(s) 2017. This article is an open access publication

\begin{abstract}
Here I examine some recent attempts to provide a new way of thinking about the philosophy of time that question the central role of 'presentness' within the definition of presentism. The central concern raised by these critics turns on the intelligibility and theoretical usefulness of the term 'is present' (cf. Correia and Rosenkrantz in Thought 4:19-27, 2015; Deasy in Nous, 2017. https://doi.org/10. 1111/nous.12109; Williamson in Modal logic as metaphysics, OUP, Oxford, 2013). My overarching aim is to at least challenge such concerns. I begin with arguments due to Deasy (Nous, 2017. https://doi.org/10.1111/nous.12109). Deasy develops a view that he calls 'transientism' and that he takes to be a well-motivated version of presentism. I show that both this way of thinking about presentism and the argument supposedly motivating it all fail. I then move to an argument due to Correia and Rosenkrantz (Thought 4:19-27, 2015). Correia and Rosenkrantz purport to show that presentism can be salvaged without making recourse to the term 'is present'. I demonstrate that their arguments fail. I then move on to a view, proposed and defended by Merricks (Truth and ontology, OUP, Oxford, 2007), Tallant (Erkenntnis 79:479-501, 2014), and Zimmerman (Philos Pap 25:115-126, 1996), and show that it has the wherewithal to meet the challenges raised by Williamson (Modal logic as metaphysics, OUP, Oxford, 2013) who, as noted above, raises genuine concerns about our capacity to define presentism.
\end{abstract}

Jonathan Tallant

jonathan.tallant@nottingham.ac.uk

1 Department of Philosophy, University of Nottingham, Nottingham NG7 2RD, UK 


\section{Introduction}

Presentism is often described as the view that 'only present objects exist' (cf. Markosian 2004: 47) and illustrated thus:

if we were to make an accurate list of all the things that exist-i.e. a list of all the things that our most unrestricted quantifiers range over-there would not be a single non-present object on the list. Thus, you and I and the Taj Mahal would be on the list, but neither Socrates nor any future grandchildren of mine would be included. (Markosian 2004: 47-8)

Others who pursue a similar definition-one that I'll call the 'standard definition' or 'traditional definition'-include Bigelow (1996), Bergmann (1999), and Crisp (2004a, b). Nonetheless, the question of how we are to define presentism (and we are to define other views in the philosophy of time) has been raised repeatedly. ${ }^{1}$ It is also the question with which I wish to engage.

Here I examine some recent attempts to provide a new way of thinking about the philosophy of time, that question the central role of 'presentness' within the definition of presentism. The central concern raised by these critics turns on the intelligibility and theoretical usefulness of the term 'is present' (cf. Correia and Rosenkrantz 2015; Deasy 2017; Williamson 2013: 24). My overarching aim is to at least challenge such concerns. I begin with arguments due to Deasy (2017). Deasy develops a view that he calls 'transientism' and that he takes to be a well-motivated version of presentism. I show that both this way of thinking about presentism and the argument supposedly motivating it all fail. I then move to an argument due to Correia and Rosenkrantz (2015). Correia and Rosenkrantz purport to show that presentism can be salvaged without making recourse to the term 'is present'. I demonstrate that their arguments fail. I then move on to a view, proposed and defended by Merricks (2007), Tallant (2014) and Zimmerman (1996), and show that it has the wherewithal to meet the challenges raised by Williamson (2013) who, as noted above, raises genuine concerns about our capacity to define presentism. In the final section(s) of the paper, I consider a revised interpretation of the Deasy/ Williamson approach that sees them presenting a broader challenge about the kinds of question we should put front and centre in our metaphysics of time. I challenge the approach and suggest an alternative.

\section{Deasy, Presentism and Transientism}

The first attempt to define presentism that we'll consider here is due to Deasy (2017). Deasy begins by arguing that presentists who would defend standard presentism must tell us what they mean by 'present' in their claim that 'only present objects exist'. After all, presence is a key component of the presentist view and so some account of what presentists mean by 'present' should be forthcoming. Sadly,

\footnotetext{
${ }^{1}$ See, for instance: Crisp (2004a, b), Ludlow (2004), Meyer (2005, 2013) Savitt (2006), Sider (2006), Stoneham (2009), and Torrengo (2016), as well as various others discussed in detail a little later on.
} 
according to Deasy, all interpretations of 'present' fail, and so what I've called the 'standard' definition fails to pick out a well-defined view. We cannot make philosophical progress without a well-defined view, and, as such, we ought to reject the standard, traditional definition of presentism. With that in hand, Deasy then proposes something more positive.

I'm not going to walk through the details of how and why Deasy rejects each account of what it is to be present that the presentist might offer, though we will have cause to examine some parts of these arguments in Sect. 3. For the time being let me simply state Deasy's proposed methodology, for this will be especially important in what follows, as well as his positive attempt to describe a presentist view.

I describe what I take to be the most plausible suggestions for what presentists could mean by 'is present' in the context of the traditional definition of presentism. In each case, I show that given the relevant analysis of 'is present', presentism so defined is either (i) trivial; (ii) too implausible to be worthwhile debating; (iii) has consequences which most self-described presentists would reject; (iv) consistent with 'rival' theories such as the B-theory and the moving spotlight theory; or (v) controversial for reasons that have nothing to do with the philosophy of time... having at least one of features (i)-(v) can reasonably be said to count against a candidate interpretation of the traditional definition. And given that there is an alternative to the traditional definition which has none of these features (described in $\$ 4$ below), the fact that every plausible interpretation of the traditional definition has at least one of them gives us a good reason to reject the traditional definition in favour of the alternative definition. (2017: 381-2)

For the time being, then, let us assume that Deasy successfully discharges his duty in his arguments against the traditional view, and shows that the traditional definitions fail; we must then turn to his positive definition [that allegedly has none of features (i)-(v)].

Deasy begins his definitional work by elaborating on how he understands the core of the A-theory. According to Deasy, the A-theory commits us to the existence of an absolute, objective present instant. This leaves the A-theory as a genus of views that includes not only presentism, but the growing block ${ }^{2}$ and moving spotlight views ${ }^{3}$ : the former maintains that past and present objects exist and that the passage of time is constituted by the steady addition of facts to the block; the latter view maintains that past and future objects exist, and that there is a privileged moment (the present) that 'moves' from past to future. Thus, to get from Deasy's A-theory to presentism, we have to add detail.

Now, Deasy's overarching concern is that in the debate about how we should define presentism (and eternalism ${ }^{4}$ ) we've been asking the wrong questions. In adding to the definition of the A-theory, we've been trying to find answers to the

\footnotetext{
2 See, inter alia, Tooley (1997).

3 See, inter alia, Cameron (2015).

4 Normally, the view described as 'past, present and future times are equally real'.
} 
'traditional questions'. These are: Are there past things? Are there future things? But for a range of reasons, Deasy thinks that answers to these questions aren't helpful to us in trying to formulate presentism. The right questions, Deasy (2017: 378) maintains, are: (i) Do things begin to exist? (ii) Do things cease to exist? He claims that the presentist should answer 'yes' to both; proponents of the growing block view of time should answer 'yes' to (i), but 'no' to (ii). The eternalist (the proponent of the view normally described as that according to which 'all times exist') should answer 'no' to both of Deasy's questions.

In Deasy's hands, presentism then amounts to the thesis that:

Deasy-definition: There is an absolute, objective present instant and sometimes, something begins to exist and sometimes, something ceases to exist (2017: 390).

I do not think that the Deasy-definition succeeds. I am going to proceed by demonstrating how definitively non-presentist scenarios would satisfy this alleged definition of presentism. The definitively non-presentist scenarios I have in mind are odd; I sincerely doubt they've ever been defended as theses about how the world is, or that they ever will be. Nonetheless, that they are clearly non-presentist and yet compatible with Deasy's definition is all that I require in order to demonstrate that Deasy's definition of presentism is one that fails.

Here are the particular non-presentist scenarios I have in mind. I'll sketch them metaphorically to begin, and then formalize them. First, consider a scenario that looks a lot like a growing block world, though is a world I dub a 'trundling block' world. To reach a description of our 'trundling block' world, let us start with a description of a growing block world. I borrow, here, from Briggs and Forbes (2017: 928)

The Growing-Block view has two commitments:

ASYMMETRIC ONTOLOGY Only past and present events exist, while future events do not. The present is thus the last time in existence.

PASSAGE The passage of time consists in events coming into existence, so that the universe is a four-dimensional block that grows as new events are added to the later end. Once events become part of the block, their intrinsic properties and their relations to earlier states are fixed forever more, but their relations to later states can change, as later states are added to the end of the block. 5

So much for the growing block. Now to the trundling block. For the first 1000 years of the trundling block world it appears exactly as would a growing block world. There is a steady accretion of events, adding to the block. However, after having existed for 1000 years in the body of this growing block, events cease to exist. 1000 years of existing is all that events do within the body of the block; then their time is up, and they cease to be. For the first 1000 years of its life, this scenario appears to be a growing block world. After 1000 years, though, the block stays the

\footnotetext{
5 Cf. Forbes (2016: 700). 'Present events, a defender of the Growing-Block view may point out, are succeeded by nothing.'
} 
same 'size', carrying on gaining new events, but now losing them, too. The block ceases growing and starts trundling through time, shedding events as it goes. So much for the gloss, now let me be more formal. This is a world where: there is an absolute, objective present instant and sometimes, something begins to exist, and when it does so it is objectively present. It then continues to exist for 1000 years, then it ceases to exist.

Such a scenario is clearly not presentist. As we said, for the first 1000 years of its life such a scenario appears identical to that posited by the proponent of the growing block (and no such scenario would be posited by a presentist). Nonetheless, the scenario would satisfy the Deasy-definition: there is an absolute present instant and sometimes things begin to exist, and sometimes, namely, after 1000 years, things cease to exist. Moreover, it permits us a perspicuous account of what it is to be present. As above in our description of the growing block borrowed from Briggs and Forbes, the present time is the time such that no objects exist later than it.

A second example of a strange non-presentist view that satisfies Deasy's definition of presentism is one that we can describe as a 'moving shadow' view, similar to that defended by the moving spotlighter. To get to this view, start with Zimmerman's (2011) version of presentism, according to which the whole of the space-time manifold exists [a 'permeable cosmic jell-o' (2011: 200)], but where objects only exist at the present moment (and times are not objects). To that spacetime manifold let us add past and future objects, but then let us also remove the present objects. According to this view, past and future objects exist, but present objects do not. Objects cease to exist when they drop out of the future and into the present time, and begin to exist again when they drop into the past. Such a view can probably be described as one that (at least in a sense) privileges the present time (if only because the idea of what it is to 'privilege' the present is never made at all precise), because the present time is unique in being unoccupied by objects, and it's certainly one according to which objects sometimes cease to exist and objects sometimes begin existing. ${ }^{6}$ Moreover, it permits us a perspicuous account of what it is to be present: for all objects, ' $\mathrm{x}$ is present' is true at $\mathrm{t}$ iff $\mathrm{x}$ exists in the past and the future, but does not exist at $\mathrm{t}$ (where ' $\mathrm{t}$ ' stands for a region or slice of space-time). Again, we render this semi-formally: there is an absolute, objective present instant and sometimes (namely, when it ceases to be present), something begins to exist and sometimes (namely, when it becomes present), something ceases to exist.

That being so, the Deasy-definition of presentism fails. It is prone to at least two countermodels. (And, of course, one would suffice.)

\section{Deasy Replies?}

Now at this point, we should be cautious. Deasy (2017: 15-16) considers the charge that his definition might not capture all and only those possibilities that we think of as being presentist. Here is one example he gives himself:

\footnotetext{
6 Thanks to Matt Leonard and Cruz Davis for discussion of the example.
} 
notice that transientism [what I'm calling 'Deasy-presentism'] is consistent with the view that exactly one thing begins and ceases to exist, while everything else exists eternally. Some might object that this view-even when combined with the A-theory-does not deserve the label 'presentism' (or at least, does not automatically deserve the label 'presentism'). (2017: 392)

If Deasy is prepared to allow that his version of presentism is compatible with this scenario, then might he simply express a lack of care about whether or not either of the two models I describe satisfy his definition? I don't think that he should. In this section, set aside my concerns (from the last section) about countermodels. I'm here interested only in this scenario that Deasy himself describes in the quotation just given. In what follows, I'll call this 'SCENARIO'.

Now, I agree with Deasy up to the following point. The view that exactly one thing begins and ceases to exist, combined with everything else existing eternally, does not deserve the label 'presentism'. His view is compatible with that scenario. So, his view does not deserve the label 'presentism'. There, we agree.

So, how does Deasy try to get himself out of this bind?

Objections such as the above do not pose a serious threat to the new definition of presentism. Indeed, some vulnerability to such objections is a sacrifice worth making for the gain in clarity afforded by the new definition.... It is difficult to say without knowing what it is to be 'present' in the sense of the traditional definition. Thus the relative obscurity of the traditional definition even infects possible objections to the new definition. It is better for presentists to operate with the new definition and thereby know exactly which theories are and are not consistent with their own. Moreover, note that philosophical progress could still be made even if presentists were to withhold the title 'presentism' from the transientist A-theory. The central thesis of this paper is that A-theorists (including presentists) should abandon the traditional definitions of their theories in favour of the new definitions described above. However, the main reason for accepting this thesis is that the new definitions-unlike the traditional definitions-express clear, opposing, philosophically substantive theses that are worth debating. As long as presentists and other A-theorists put these theses at the heart of their theorising- even if they do not label them 'presentism', and so on-progress can be made in the philosophy of time. (2017: 392-3)

This argument strikes me as problematic due to an internal inconsistency in Deasy's line of argument.

I begin with a walk-through of some of Deasy's objections to specific attempts to define 'traditional presentism' and show that he cannot maintain the position just described and reject traditional presentism, given his methodological commitments.

Deasy's argument begins by acknowledging that traditional presentists would reject his account of what it is to be presentist. They would reject what I'm calling Deasy-presentism. And I think that he's quite right. SCENARIO is non-presentist, but compatible with Deasy's definition. 
Deasy's argument then moves to saying that this doesn't matter because we now have greater clarity in the debate: his (what he calls) transient-presentism is clearer, and more rigorously defined than standard versions of presentism. As above (2017: 393): "the main reason for accepting this thesis is that the new definitions-unlike the traditional definitions-express clear, opposing, philosophically substantive theses that are worth debating.' But, as I'll show, that then leaves him facing a problem with earlier parts of his argument. ${ }^{7}$

Earlier on in the paper, Deasy (2017: 383) considers one way to understand presentism, as a thesis about what is fundamental:

PRESENTISM 2. Always, everything instantiates fundamental presentness

But, Deasy says, there are two problems with this. First, he identifies one presentist, Zimmerman (1996: 118, n8) and then quotes Zimmerman: 'no real presentist has any reason to believe in a special quality of "being present" (and, indeed, no articulate presentist that I know of has ever posited such a quality)'. Deasy (2017: 383) himself then says that: 'normal self-described presentists [like Zimmerman] have explicitly rejected the thesis that presentness is fundamental'.

Now that's true, of course. The quote is accurate. But lots of presentists have also argued that their position is incompatible with the existence of past-objects-the existence of which is permitted by Deasy's definition of presentism, as Deasy himself allows in SCENARIO. If what's good for the goose is good for the gander, then this is a problem. Deasy's view is compatible with the existence of past objects. Lots of presentists (all traditional presentists?) have explicitly stated that their position is not compatible with the existence of past objects. So, Deasy-presentism can't be what presentists are interested in and, if PRESENTISM 2 is to be rejected, so is Deasy-presentism. ${ }^{8}$

The only other point that Deasy offers against PRESENTISM 2 is that:

if presentism is presentism 2 then the debate between presentists, growing blockers and moving spotlighters reduces to a debate about whether everything or only some things instantiate fundamental presentness. However, that sounds more like a parody of the philosophy of time than a substantive philosophical debate (Deasy 2017: 7).

But this seems wrong (as well as unclear-why agree with Deasy that this would be akin to parody? It's not enough to simply assert that, surely, in order to reject an opposing position.). Here is one way that the debate could go. The presentist could endorse a fundamental feature of presentness. The eternalist may deny that there is any such feature. In that case the debate between the two does not reduce to a debate about whether everything or only something instantiates fundamental presentness. Rather, the debate would then turn upon whether or not such a feature of presentness

\footnotetext{
7 I'll also dispute Deasy's claim that his approach manages to preserve these other virtues in Sects. 5.1 and 5.2.

${ }^{8}$ Moreover, there are presentists who have argued that a view that does treat presentness as fundamental has been articulated and defended in the wider literature, motivating it via arguments that show it can deal with various problems facing other versions of presentism. See Baron (2014). We might not like Baron's position, but it won't do to simply dismiss it without engagement.
} 
were comprehensible, whether it had explanatory power, whether it helped solve problems in need of solution, and so on. ${ }^{9}$ In other words, the debate would reduce to a debate about the metaphysics of time.

In any case, my point is not that PRESENTNESS 2 represents the right way to think about presentism. My point is just that Deasy cannot rule out PRESENTNESS 2 as a definition of presentism on the grounds that it has certain features, and then present his own view as a natural successor despite the fact that it has those features. That is, he cannot rule out PRESENTNESS 2 on the grounds that it commits us to something that one presentist denies, whilst then endorsing, via SCENARIO, a possibility that most presentists deny.

Nor is this an isolated case. Deasy (2017: 384-5) appears to reject other views in a structurally similar fashion: showing that the standard definition isn't compatible with some things that presentists might want to say, and thus moving to reject the attempted definition. For instance, 'Always, everything with a temporal location is spatially located' is rejected on the grounds that it commits us to denying that there are non-spatially located mental events. ${ }^{10}$ But, again, this argument just seems bizarre when conjoined to the definition of presentism that Deasy gives. Surely, those who propose the standard definition would sooner give up on the existence of the non-mental than they would admit the existence of past objects. If it's ok for Deasy to allow that his definition doesn't necessarily deserve the sobriquet 'presentism', but that this is ok, because we can now use his way of characterizing a position to move the debate forward, it's opaque (for everything that Deasy has said) as to why we can't use the likes of PRESENTNESS 2 to do the same.

Indeed, and now we return our attention to his stated methodology, it should be obvious that there is a flaw to Deasy's approach. On the one hand, he claims (2017: 381-2) that we have reason to reject a candidate interpretation of presentism it has any of features (i)-(v), where those include: (iii) has consequences which most selfdescribed presentists would reject; (iv) consistent with 'rival' theories such as the B-theory and the moving spotlight theory. He also claims that his version of presentism lacks those features. Deasy then (2017: 392-3) commits an abrupt aboutturn and says that his view does have those features, but that it doesn't matter to his definition if it has features like (iii) and (iv), because now we have greater clarity in the debate. But, as we've just seen, clarity wasn't on the table when we were rejecting earlier versions of presentism, like PRESENTNESS 2. What was of concern, there, was whether we were accurately capturing the core of traditional versions of presentism. Given his own methodological commitments, Deasy should therefore reject his own view.

\footnotetext{
9 And not everyone will think that such presentness does the required work. One early critic of the notion that a rich notion of presence is required is Williams (1951). See, especially, (1951: 461-3). Well and good. Of course, those explicitly defend PRESENTNESS 2 (e.g. Baron 2014) will think that it does. Rather than dismiss them out of hand, we should engage with such views. Indeed, given that there are those who would regiment metaphysics generally as a quest for the fundamental (e.g. Schaffer 2009), Deasy's move seems much too quick. See Sects. 5.1 and 5.2, and fn 27, for further discussion.

${ }^{10}$ Note that Deasy subsequently remarks of this objection that it shows that presentists cannot define their view in this way. 'Presentists should reject presentism 2 as the correct interpretation of the traditional definition' (2017: 383).
} 
We have two objections to Deasy's view. It is prone to countermodels. It is motivated by an internally inconsistent line of argument. Perhaps there are modifications to be made, and other ways to motivate the view. In that case, we should be told what they are.

\section{Correia and Rosenkrantz}

Let us suppose that, in Deasy's own hands, the execution of his overall strategy may misfire in several respects. But, it may appear, he also has a point—already at least gestured towards by Williamson (2013: 24-5) on whose work Deasy plausibly relies-viz. that the relevant notion of presentness seems to be too elusive to be at the service of metaphysical theorizing. ${ }^{11}$

Even if the specific arguments that Deasy offers aren't persuasive, we still have the Williamsonian position to fall back on. Progress might still be made by reformulating the contrast between competing views on time in other terms. In this spirit, Correia and Rosenkranz (2015) recently offered a characterization of presentism, using the kinds of resources Deasy deploys, which, unlike Deasy's definition, is arguably immune to the criticism levelled above. I think that it, too, fails, however. I begin by presenting their definition before moving to three reasons to reject it.

The definition that they offer (2015: 24) turns on two notions: that of being one off and that of a time. We can define one-off, thus: $m$ is new iff always in the past, $m$ does not exist; $m$ is doomed iff always in the future, $m$ does not exist; $m$ is in time iff sometimes, for some time $t, m$ is contemporaneous with $t$. Then: $m$ is one-off iff $m$ is both new and doomed (2015: 22). 'Times' here is understood flexibly. Times may be regarded as entities sui generis or as reducible to collections of point-sized events, states or tensed facts (2015: 27, fn3).

From there, we define presentism thus:

Always, $\exists t(t$ is one-off $\& \forall x(x$ is in time $\rightarrow x$ is contemporaneous with $t))$ $(2015: 24)^{12}$

Here are three reasons to dislike Correia and Rosencrantz's definition of presentism.

First, a reservation about scope. By Correia and Rosencrantz's own lights (2015: 22), theirs is an attempt to preserve the dispute between presentist and eternalist in fresh terms. But now consider the position of a self-avowed presentist, Zimmerman (2011) according to which only present objects exist, but where there nonetheless exists a 'permeable cosmic jell-o' (2011: 200) that is to be identified with spacetime. This space-time spans not only the present, but also the past and future. Correia and Rosencrantz would not classify Zimmerman as a presentist: he would reject the claim that $\exists t t$ is one-off. If they rule Zimmerman's position non-

\footnotetext{
11 I'm very grateful to a referee for another journal for this point.

12 Where ' $t$ ' is a variable for times.
} 
presentist, it is not clear that Correia and Rosencrantz have succeeded in their attempt to preserve the dispute between presentist and eternalist in fresh terms. ${ }^{13}$

Second, there is a sense that something is missing from their account. Borrowing from Merricks, the distinction between presentism and eternalism must include a difference in how we understand existence.

'consider a view that starts off with the eternalist's picture of time and existence at a time, and then 'shaves off' the past and future, leaving only a thin (instantaneous?) slice called 'the present'. This view agrees with eternalism that existing at a time-any time, past, present, or future-is like being located at a place. But, unlike eternalism, this view says that while objects exist at the present time, they exist at no other times, since there are no other times at which to be located. (2007: 124)

Merricks does not think that this is an appropriate way in which to describe presentism. I agree.

I can see why some might think this view is presentism. They think that this view is presentism because they (wrongly) ascribe to presentists the eternalist's claim that to exist at a time is to be located at some super-thin slice of being. But presentists should no more accept this than the nonLewisian should accept that to possible exist is to be located in some universe. (2007: 124)

Of course, for all that Correia and Rosencrantz say, their view is compatible with this way of thinking about presentism. They are explicit (2015: 25) that their notion of 'being contemporaneous with' is the same as being at that time. To that extent, it looks as if they ignore Merricks' exhortation to not treat time as some super-thin slice of being, at which we find located all existing objects. At least, if they have not ignored it, then Correia and Rosencrantz have left out some important feature of their definition of the view-what it is to 'be contemporaneous with' that isn't just a matter of existing at a time. And it certainly seems as if they are ignoring the thrust of Merricks' point. As they (2015: 22) put it: 'the relation of contemporaneity deployed in the latter equivalence... is the one familiar from standard B-theories'. Merely conjoining a range of objects to that B-relation of contemporaneity doesn't seem to generate anything more than the super thin slice of being, to which Merricks objects. To that extent, we may wish to reject their position.

Third, the definition offered by Correia and Rosencrantz looks to fail outright. Begin with:

C\&R-PRES: Always, $\exists t(t$ is one-off \& $\forall x(x$ is in time $\rightarrow x$ is contemporaneous with $t$ ))

Recall, also, the definition of what it is to be in time.

IN-TIME: $m$ is in time iff sometimes, for some time $t, m$ is contemporaneous with $t$ (2015: 22).

\footnotetext{
13 Nor is Zimmerman alone in this regard. Fiocco (2007: 192) also makes it clear that he thinks that a presentism can accommodate the existence of non-present times.
} 
Note that IN-TIME, as stated, means that the dinosaurs are 'in time': that is, sometimes, for some time, $t$, dinosaurs are contemporaneous with $t$. And that, of course, is as it should be. Dinosaurs are 'in time', in the sense that they have been present - at some time they are contemporaneous with t. Note also, however, that C\&R-PRES stipulates in its second clause that being in time is sufficient for being contemporaneous with the time that exists.

Thus, let us substitute IN-TIME into C\&R-PRES:

C\&R-PRES-SUB: Always, $\exists t\left(t\right.$ is one-off $\& \forall x$ (sometimes, for some time, $\mathrm{t}^{\prime}$, $\mathrm{X}$ is contemporaneous with $\mathrm{t}^{\prime} \rightarrow x$ is contemporaneous with $\left.\left.t\right)\right)^{14}$

That being so, if dinosaurs are 'in time' (and, as above, they are), then it would follow from C\&R-PRES-SUB that the dinosaur's being in time is sufficient for their existing at the one existing time-the present. And that, surely, is false. Dinosaurs are 'in time' but are not present. Call this the 'in time' objection

Correia and Rosenkrantz will want to avoid the 'in time' objection. Indeed, they look to try to pre-empt something like this concern. In what follows I'm going to argue that their way of avoiding the 'in time' objection commits them to the existence of one (and only one) time, and that this, in turn, means that they are unable to deploy their preferred way of avoiding the 'in time' objection.

In outline the argument runs as follows: to avoid the charge that dinosaurs are in time', and so avoid the charge that their definition of presentism commits us to the existence of present dinosaurs, Correia and Rosenkrantz would have us endorse a specific account of what it is to be 'one off'. That account of what it is to be one off commits us to the truth of a principle that we will come onto in a moment: $\forall \mathrm{t} \forall \mathrm{t}^{\prime}\left(\mathrm{t}^{\prime}=\mathrm{t}\right)$. In turn, that commits us to the existence of an ever-unchanging time-slice-and no such position is presentist. That being so, Correia and Rosenkrantz face a dilemma: they must commit to the false claim that there are presently existing dinosaurs, or else they must commit to a view that isn't presentist. First, I must spell out the formal details of their response to the 'in time' objection, in order to see how and why they are committee to $\forall \mathrm{t} \forall \mathrm{t}^{\prime}\left(\mathrm{t}^{\prime}=\mathrm{t}\right)$, which in turn enables me to show how their view fails.

Here, then, is their attempt to avoid the 'in time' objection.

suppose that $\mathrm{t}$ is future. By (ii), at $\mathrm{t}, \mathrm{t}$ exists. So, sometimes in the future, $\mathrm{t}$ exists. But then if $\mathrm{t}$ also existed now, it would not presently be doomed. Similar considerations show that $t$ could not be some past time given that $t$ is new. In this reply, we rely on the inference from ' $t$ is a future/past time' and 'At t, $\varphi$ ' to 'Sometimes in the future/past, $\varphi$ '. (2015: 24).

Making sense of this claim requires us to make sense of what it is that they mean by 'doomed' and 'new'.

' $m$ is new iff always in the past, $m$ does not exist'

' $\mathrm{m}$ is doomed iff always in the future, $\mathrm{m}$ does not exist'.

Since Correia and Rosenkrantz specify that $\mathrm{m}$ is one-off if and only if $\mathrm{m}$ is both new and doomed, so it seems that my objection is ill-formed, for dinosaurs are not to be

14 Where t' and t are both simply variables. 
regarded as 'one off'. They are not new: it is not the case that, always in the past, dinosaurs do not exist. Now, here comes the problem for my 'in time' objection. As Correia and Rosenkrantz note (2015: 22) their claim that time is a one-off, seems to be such that it generates the result that every time as a one off.

In their own terms,

By the characterisation of being in time, it follows from $\left(1^{*}\right)$ that always every time is one-off; and thus, if we use ' $t$ ', ' $t$ ' ' etc. for time-variables, we get:

(2) Always, $\forall \mathrm{t}(\mathrm{t}$ is one-off)

And, as they go on to note, that seems to be compatible with the thesis that more than one time exists. If more than one time exists, then C\&R-PRES-SUB is satisfiable by a number of times ranged over by the variable $t$. That is, it would be compatible with a model in which objects exist at more than one time, where each such time is defined near-trivially as a one-off. That, let us say, is not presentism. They must resist this appearance.

Happily, claim Correia and Rosenkrantz (2015: 22-3), appearances are deceptive and their position - that is, that which underpins their pre-empting response to the 'in time' objection-is not compatible with the existence of more than one time. I reproduce the formalism of their argument.

(i) $\quad \mathrm{t} \neq \mathrm{t}^{\prime} \rightarrow \mathrm{t}<\mathrm{t}^{\prime} \vee \mathrm{t}^{\prime}<\mathrm{t}$

(ii) At t, t exists

(iii) $\quad \mathrm{t}<\mathrm{t}^{\prime} \&\left(\right.$ At $\left.\mathrm{t}^{\prime}, \varphi\right) \rightarrow$ At $\mathrm{t}$, Sometimes in the future, $\varphi$

(iv) $\mathrm{t}^{\prime}<\mathrm{t} \&\left(\right.$ At $\left.^{\prime}, \varphi\right) \rightarrow$ At $\mathrm{t}$, Sometimes in the past, $\varphi$

(v) (At t, $\varphi) \&$ At $t,(\varphi \rightarrow \psi) \rightarrow$ At $t, \psi$

(vi) For $\varphi$ tautologous: At $\mathrm{t}, \varphi$

(vii) $\varphi \rightarrow \exists \mathrm{t}$ At $\mathrm{t}, \varphi$

(viii) (At t, $\neg \varphi) \rightarrow \neg($ At $\mathrm{t}, \varphi)$.

Now, assume for reductio that there are two distinct times, $t$ and $\mathrm{t}^{\prime}$.

By (i), either $\mathrm{t}<\mathrm{t}^{\prime}$ or $\mathrm{t}^{\prime}<\mathrm{t}$.

Suppose that $\mathrm{t}<\mathrm{t}^{\prime}$

We may then derive:

(a) At $t, t^{\prime}$ is not one-off

(b) At $\mathrm{t}^{\prime}, \mathrm{t}$ is not one-off.

Each of $\mathrm{t}$ and $\mathrm{t}^{\prime}$ is one-off, so together with (vii), this entails that there is a time $\mathrm{t} 0$ at which this is the case, and so by (v) and (vi) we can derive:

(c) At $\mathrm{t} 0, \mathrm{t}$ is one-off

(d) At $\mathrm{t} 0, \mathrm{t}^{\prime}$ is one-off.

By (a), (d) and (viii), $\mathrm{t} \neq \mathrm{t} 0$. Accordingly, by (i), either $\mathrm{t}<\mathrm{t} 0$ or $\mathrm{t} 0<\mathrm{t}$.

But, as they explain, neither disjunct is possible. If $\mathrm{t}<\mathrm{t} 0$, then [given (ii), (iv), (v) and (vi)], at $\mathrm{t} 0, \mathrm{t}$ is not one-off. That contradicts (c), given (viii). 
If, on the other hand, t0 $<\mathrm{t}$, then [given (ii), (iii), (v) and (vi)], at $\mathrm{t} 0, \mathrm{t}$ is not oneoff. That again contradicts (c) given (viii). Hence we must reject the assumption made for reductio: that there are two distinct times. Given the generality of the proof, it follows that:

(3) Always, $\forall \mathrm{t} \forall \mathrm{t}^{\prime}\left(\mathrm{t}^{\prime}=\mathrm{t}\right)$.

Thus, there exists only one time. So provided we allow them their definition of 'one off', Correia and Rosenkrantz can avoid the 'in time' objection.

The trouble with the kind of move that Correia and Rosenkrantz make runs as follows. Correia and Rosenkrantz do not in fact tell us explicitly what they take either $<$ or $>$ to denote, but let us charitably assume that they mean 'earlier than', or 'later than'. Note, then, that given their claim that there exists only one time [their (3)], it then follows that we have only one time to work with in our theorizing. But now recall the definition of 'new': ' $m$ is new iff always in the past, $m$ does not exist'. 'Always in the past' is but a disguised way of saying 'at every past time, $\mathbf{t}^{\prime}$. That being so, new means ' $\mathrm{m}$ is new iff at all past times $\mathrm{t}, \mathrm{m}$ does not exist.

But, of course, it follows from (3) that any putative past time, $t$, is identical to the present time, $\mathrm{t}^{\prime}$. There $i s$ but one time, remember: Always, $\forall \mathrm{t} \forall \mathrm{t}^{\prime}\left(\mathrm{t}^{\prime}=\mathrm{t}\right)$. And if the putative past time $t$ is identical to the present time $t^{\prime}$, then it follows that no presently existing object is doomed and that no presently existing object is new. After all, there is no past time $\mathrm{t}$ or future time $\mathrm{t}^{\prime \prime}$, such that $\mathrm{t}$ or $\mathrm{t}^{\prime \prime}$ is a time which is distinct from the present time, $\mathfrak{t}^{\prime}: \mathrm{t}=\mathrm{t}^{\prime}=\mathrm{t}^{\prime \prime}$.

So, as soon we as accept (3), we must conclude that there is only one time. More, since at every time $\mathrm{t}^{\prime}, \mathrm{t}=\mathrm{t}^{\prime}$ (because there is only one time to be $a t$ ), it follows from (3) that: always, t exists. And since the only objects that exist at t are those that now exist at $\mathrm{t}$, it follows that all and only the objects that now exist at $\mathrm{t}$, always exist. What Correia and Rosenkrantz have described, therefore, is not a presentist world where what exists changes from moment to moment, but a world in which it is always the case that what exists right now is all that exists. At least so far as I can tell, that is not presentism, either. Presentists do not believe in the existence of a single, unchanging time-slice: such a view is false; there is more to the reality than a single and unchanging time slice.

So, to recap, here is the last concern in full: to avoid the charge that dinosaurs are 'in time', and so to avoid the charge that their definition of presentism commits us to the existence of present dinosaurs, Correia and Rosenkrantz would have us endorse a specific account of what it is to be 'one off'. That account of what it is to be one off commits us to the truth of (3); $\forall \mathrm{t}^{\prime} \mathrm{t}^{\prime}\left(\mathrm{t}^{\prime}=\mathrm{t}\right)$. In turn, (3) commits us to the existence of an ever-unchanging time-slice; a view we would do well to reject.

That being so, Correia and Rosenkrantz face a dilemma: they must commit to the false claim that there are presently existing dinosaurs, or else they must commit to the false view that there is a single unchanging timeslice. Either way, this does not seem to be a good result for presentism.

In closing this section, let me note that I am sympathetic to the way of proceeding suggested by Correia and Rosenkrantz. Although there seem to be challenges to their account - and I've raised three of them here-theirs is an interesting route to 
pursue. Perhaps their account can be patched. ${ }^{15}$ But, in the absence of such a patch, I shall turn my attention to different ground.

\section{New Accounts or Old?}

As should be clear, I think that prospects for these kinds of new approaches to debates in the philosophy of time are still somewhat under-motivated or else require more attention. Still, and as Corriea and Rosenkrantz (2015: 22) make clear, the point - already made by Williamson (2013) — that the relevant notion of presentness seems to be too elusive to be at the service of metaphysical theorizing, may still be troubling. And if we do not pursue the solution offered by Corriea and Rosenkrantz, what are we to do? Of the Williamsonian view they say:

However, his conclusion that we should articulate the debate in such a way that the traditional oppositions no longer figure, seems to us to be both highly implausible and premature. (2015: 22)

But if their view fails, what is left to us aside from conceding to Williamson? Before giving up on the old way of proceeding, we should perhaps turn to Williamson's arguments. What does he have to say, directly, about the presentism versus eternalism debate, and what is wrong with it?

As it goes, not that much. Williamson's primary target in Modal Logic as Metaphysics is the distinction between theories of modality (2013: 4), with some links to the debates in the philosophy of time being flagged 'for illustration or interest'. It is for that reason, I suspect, that Williamson's attack on the distinction between presentism and eternalism is somewhat brief (2013: 24-5), and, quite understandably, does not run through all of the various ins and outs of the competing definitions of presentism. His chief complaint, though, is that the presentist has no good account of what it is to be present (2013: 24). This is a metaphysical complaint. For presentism to be viable, we must hear much more about the metaphysics of what it is to be present.

To an extent, the complaint is entirely reasonable. Few presentists have much to say about the details of what it is to be present. But there are some exceptions. In particular, in this final section of the paper, I want to pursue a view (or, given that they diverge slightly from one another, a family of views) that equates existence and presence. I show how this view allows us to respond to Williamson's concerns. I don't argue here that the view is correct (such arguments are offered elsewhere in the literature - see the citations that follow). Rather, I take it to be a potential virtue of the view that it enables us to form a coherent response to Williamson's objection.

First, let me outline the view itself. The view I have in mind is defended by the likes of Merricks (2007) and Zimmerman (1996); I've also defended it (2012, 2013, 2014). What these views do is draw a distinction in kind between the position

\footnotetext{
15 See fn 27 for further comment on their way of proceeding in the context of the approach that I outline there.
} 
adopted by presentist (on the one hand) and eternalist (on the other). Here, for instance, is Merricks (2007: 105-my italics):

I think presentists should, ..., say that existing at the present time just is existing.

In something of a similar vein, I (2014: 494) define (my preferred version of) presentism as the view that, existence is presence, further clarifying the view by remarking that: 'Presence is existence is an identity claim.' Last, consider from Zimmerman (1996: 117): 'to be present just is to be real or to exist'. ${ }^{16}$ In each case, the claim is made that this marks a genuine distinction between presentism and eternalism. According to Merricks, presentists should claim that existing at the present time is existing; eternalists must deny this. If this way of characterizing the debate between presentist and eternalist is correct, then this is a fight about an identity claim: which way of characterizing the nature of existence is correct?

In the current context, we are concerned with metaphysics. Specifically, we want to be told more about the metaphysics of presence. In order to help us meet this need, it might be useful to review my (2014) strategy. ${ }^{17}$ As above, my view is that 'existence is presence' - what I call, 'Existence Presentism'. My strategy is to show how to make sense of this identity claim ('existence is presence') given a range of views about what existence is. ${ }^{18}$ I'm not going to walk through all of those arguments. All that I want to do is to use one illustrative conception of this 'Existence Presentism' in order to show how this family of views (defended by me, Merricks and Zimmerman) has the resource to deal with Williamson's concern.

Borrowing from my earlier temporal part $(2014$; 495), let us turn to a Quinean/ Lewisian conception of existence. To bring out the core of the Quinean/Lewisian conception of existence, I quote from Van Inwagen (2008: 37).

you can say that existence is a property of you want to. No harm in it. If existence is a property, it is the property something has if and only if it exists, if and only if there is such a thing as it. That is, just as wisdom is the property that corresponds to the open sentence " $\mathrm{x}$ is wise", existence is the property that corresponds to the open sentence "x exists", and that open sentence is logically equivalent to this one: "There is something that is $\mathrm{x}$ ". If you want to talk in that way, however, you should keep it firmly in mind that existence, so conceived, is a wholly uninteresting property.

If this account of existence is correct, then, I suggest, this 'wholly uninteresting property' of existence is the property of presence.

\footnotetext{
16 This seems to mark a different stage in Zimmerman's thinking from the presentism he adopts in his (2011).

17 Simply, I think that my (2014) devotes more time and space to the details of the metaphysics of the position than do the other members of the group.

18 In the course of the paper I consider a Quinean view (2014: 495), a McGinn style view (2014: 495), a Frege/Russell view (2014: 495-6), what we might call a 'category' view (2014: 496) and a truthmaker view (2014: 496-7) — this last being drawn from my earlier (2012).
} 
To deliberately mis-quote Van Inwagen: presence is the property that corresponds to the open sentences ' $x$ exists' and ' $x$ is present'-and those sentences are logically equivalent to this one: there is something that is $\mathrm{x}$ '. (Tallant 2014: 495)

No non-presentist could endorse this view for according to no other view does an object qualify as present merely by existing (though it may qualify as present at $t$, for some value of $t$, but that is quite a different thing — cf. Tallant 2014: 498). So, it cannot be the case, according to other views, that presence is the property that corresponds to the open sentences ' $x$ exists' and ' $x$ is present' 19

With that sketch in hand, how does this help us to respond to Williamson? Well, as above, we now have an account of what presence is; it is identical to the property of existence. Perhaps there are problems with that view (more of which in a moment), but it does give us an explicit and clear statement of what presence is. That being so, we can, at the very least, respond to the concern that we lack a clear account of presence.

What, then, are Williamson's other concerns? Well, Williamson's concerns (2013: 24-5) all stem from objections to account of presence that he thinks might be offered by the presentist. Indeed, so far as I can tell, the only substantial worry that Williamson raises is with the suggestion that we might treat presence as equivalent to being spatially located. ${ }^{20} \mathrm{He}$ then notes:

But then presentism entails that everything is spatially located, and so is incompatible with the platonist thesis that there are spatially unlocated abstract objects. But presentism was not supposed to have such ramifications for the philosophy of mathematics. (2013: 24)

Now of course, the Merricks/Tallant/Zimmerman position is slightly different. It claims that existence is presence, rather than making a claim about the spatial location of abstract objects. Nonetheless, the Merricks/Tallant/Zimmerman position might be taken to be incompatible with the platonist thesis that there are temporally unlocated abstract objects. ${ }^{21}$ And, once again, we might worry: presentism was not supposed to have such ramifications for the philosophy of mathematics.

Be that is it may, it's a little hard to see what the real concern is. To borrow from my earlier self:

the proponent of EP [what I'm treating as the Merricks/Tallant/Zimmerman position], may simply endorse the view that such objects are changeless, but

\footnotetext{
${ }^{19}$ I won't engage any further in the exegesis of the view, or in explaining why I take the position to generate a sensible response to the charge that presentism is either trivial or false. My more limited goal is simply to show that the family of views, of which I am but one representative, enables us to respond to the kinds of concern that Williamson (2013) raises.

${ }^{20}$ Williamson (2013: 24-5) also raises a concern about the semantic function of 'is present'. He worries that 'is present' makes no difference to the truth value of a sentence, when within the scope of a temporal operator. Whilst that may be true, it isn't obviously relevant here. The Merricks/Tallant/Zimmerman position is a metaphysical thesis, not a claim about the function of 'is present'.

21 Indeed, I do (2014: 499) worry that I'm committed to there being no non-temporal abstract objects and then move to address this concern.
} 
presently existing, objects. By virtue of existing unchanging at all times, abstract objects are-in a sense-timeless. But on this reading of what it is to be timeless, abstract objects get to be timeless whilst also existing, presently, at each time. The view, though revisionary, seems reasonable. Certainly, it's a little hard to see why the proponent of EP may not adopt such a view. (2014: 499)

To be sure, we might not have expected presentism to throw up the result that abstract objects exist in time. But presentism is a philosophy of time. One thing that is surely within the purview of a philosophical position about the nature of time, is the scope and limit of time and what it is to be temporal or atemporal. So, one reasonable question for a philosophical position about the nature of time to deliver an answer to is: is it possible to be 'outside' of time? Presentism, at least so described, says not. Abstract objects are temporal—if unchanging. But, once more, it's hard to see that as a genuine concern. For all that has been said, then, it's hard to see why we might not continue the debate between presentist and eternalist, framed in the traditional way, understanding presentism as me Merricks, and Zimmerman would suggest that we do.

To be clear, I think that Williamson sees the option that I present as open. Williamson (2013: 25) notes the option of considering more refined definitions of presentism (definitions such as that which I present here). He prefers not to: 'it is better to make a fresh start with fresh terminology and clearer distinctions' (2013: 25). But, contra Williamson, I take it that the terminology deployed here (at least in these 'existing presentisms') is perfectly clear.

There is a potential reply available. An opponent might allege that my reply misunderstands Williamson's complaint. What is missing, Williamson thinks, is an account of what 'is present' is supposed to mean. That is, in the context of the metaphysics of time, what does 'is present' add to our theorizing such that one can assess claims such as 'nothing is non-present' or 'all things are present'? In contrast, claims my opponent, what these 'existing presentisms' are doing is looking to make a substantial claim about the metaphysics that underpins our talk of existence/ presence. The two projects are orthogonal.

By way of reply, let me concede ground. Perhaps my opponent is right about what is going on in the dialectic. But, even so, I think that the presentist-at least, the existing presentist-survives unscathed. If we can understand existing presentism (and I think that we can), then I'm happy for us to set to one side definitions of presentism that describe it as the view that 'nothing is non-present' or that 'all things are present'. If the terminology is as obscure as Williamson suggests, then so be it. Nonetheless, there seems to be nothing so obscure about the existing presentist case. (At least, no such concerns have been raised in the literature.) We can therefore persist with at least that understanding of presentism. That being so it is, I think, perfectly reasonable to continue with (at least those parts of) the current terminology, as well as the current positions. 


\subsection{Re-shaping, Not Rejecting}

Here is another objection to my approach. Deasy and Williamson aren't just articulating an account of what presentism is, they're articulating a case for a reshaping of the debate. Now, perhaps that re-shaping doesn't get us presentism-as classically conceived. Perhaps that's the moral we ought to take from Sect. 2. But perhaps that's a price worth paying. Having consequences that the majority of presentists would reject can be seen as $a$ reason for rejecting a proposed definition of 'is present'.

But that doesn't mean that any proposed definition of presentism must be rejected (as a view) if it has those consequences. Rather, it's a surmountable defect of Deasy's view (transientism) that it has consequences that most presentists would reject. How might this defect be surmounted? Well, this is metaphysics. We engage in 'weights and balances' reasoning; we weigh up the costs and benefits of a particular view and then compare those against the costs and benefits of an opposing view. The view with the best amalgam of costs and benefits wins. In Sect. 2 we saw that Deasy alleges - though, I suggested, is seemingly not able to substantiate the claim that - opposing views have a number of costs. Setting that to one side, for a second, what are the claimed advantages of his account? We will have to evaluate these, if we are to find at all attractive his way of proceeding.

First note Deasy's definition of three competing A-theoretic views.

"I suggest, therefore, that each of the A-theories should be identified with the conjunction of the A-theory and the relevant answer to the new questions, as follows:

- PRESENTISM: There is an absolute, objective present instant (THE A-THEORY) \& sometimes, something begins to exist and sometimes, something ceases to exist (TRANSIENTISM)

- THE GROWING BLOCK THEORY: There is an absolute, objective present instant (THE A-THEORY) \& sometimes, something begins to exist and nothing ever ceases to exist (PASTISM)

- THE MOVING SPOTLIGHT THEORY: There is an absolute, objective present instant (THE A-THEORY) \& nothing ever begins to exist and nothing ever ceases to exist (PERMANENTISM)

Defining the A-theories this way carries a number of advantages." (Deasy 2017: 392-3)

He then articulates four such advantages. In what follows, I give each of Deasy's claims, rejecting them as I go.

"First, it makes it essential to the A-theories that they are A-theories. In particular, this means that presentism is inconsistent with the B-theory by definition, which seems correct." (2017: 391)

Well, all definitions of presentism seek inconsistency with the B-theory (e.g. Markosian 2004; Crisp 2004a, b) and those considered viable are supposed to have 
achieved just that. As to rendering it essential to A-theories that they are A-theories: it's hard to see what's at issue here or where the benefit is supposed to come from. For instance, not all presentists self-describe as A-theorists (see my 2012; Rasmussen 2012, 2015). This is because the A-theory is frequently defined as the view that there are A-properties-something that those presentists deny. ${ }^{22}$ So, certainly: if we offer Deasy's conception of what it is to be an A-theory, then it turns out that all of the A-theoretical views are essentially A-theoretic. But that's not necessarily interesting or something that we should have been hoping for. It's therefore hard to see that Deasy has offered as a genuine advantage of his account.

"Second, the theses of transientism, pastism and permanentism are clear and easily understood theses which can be straightforwardly expressed in standard temporal-logical terms." (2017: 392)

They are clear. We can grant Deasy that. But clarity is only so interesting. To recall the discussion from Sect. 3: Presentness 2 was clear. It was also rejected. It was rejected because Deasy asserted that a debate about which objects are fundamental sounded like a parody of a proper debate. Presentness 1 was rejected because it has consequences that most presentist would reject. Well, per Sect. 2, there are a number of models consistent with transientism that: sound to me like a parody of a defensible view in the philosophy of time; are certainly such that all presentist would reject (in particular, I have in mind the moving shadow view, discussed in Sect. 2). On that basis, despite the clarity that it brings it isn't at all clear that transientism is an especially important view. Thus, clarity might be of some value, but there's much more needed than that.

Third, given the new definitions each version of the A-theory is clearly inconsistent with the others. (2017: 392)

This is true. But, again, not all presentists are A-theorists (in their own terms). That being so, it isn't entirely clear what is meant to be at issue (and, in any case, see the next point).

Finally, and perhaps most importantly, the question of which of transientism, pastism or permanentism is true given the A-theory...is a substantive and interesting philosophical question. (2017: 392)

Responding to this point will take a little longer; I justify this use of the space on the grounds that Deasy appears to think that this is the most important point.

First, consider a putative model, inspired by one of Deasy's own (2017: 392). Though the view is odd, it consists in the combination of positions that have each been defended in the philosophical literature in the last few years.

Suppose that the following is true:

SIMPLICITY: Always, everything is always mereologically simple (cf. Deasy 2017: 392)

\footnotetext{
22 Those who describe the A-theory in this way include, but are not restricted to: Markosian (2010), Rasmussen (2012, 2016), Smart (2008), Tallant (2012), and Zimmerman (2008)
} 
Add to this that there is only one object that exists. That is, endorse Schaffer's (2007) Existence Monism. Let us further allow that the One existent comes into being, but never goes out of existence. (We have a big bang, but no universe-ending event.) Further, let us suppose that the world is with respect to time as I say it is: existence is presence. Call this union of views 'Parmenedianism'. There's a temptation to call this Parmenedian world a presentist world. After all, existence is presence; there are no non-present entities.

But note, this is not so given Deasy's classification. The Parmenedian position just described satisfies Deasy's definition of a growing block world: there is an absolute, objective present instant and sometimes, something begins to exist and nothing ever ceases to exist. Note, next, that Parmenedianism is a candidate for the actual world. At least, mereological nihilism has been defended and discussed reasonably widely and it isn't totally implausible to think that Existence Monism is the best form of nihilism (cf. Schaffer 2007). The claim that existence is presence has been defended, too. We are, thus, at least off to the races with Parmenedianism (as I've described it), even if we aren't yet able to say that we've backed a winner. Now, with Parmenedianism in the background, three concerns, in increasing order of magnitude, about Deasy's claim that the question of which of transientism, pastism or permanentism is true given the A-theory is a substantive and interesting philosophical question.

First, how philosophically interesting a question is looks in significant part to be a function of the answers that can be given to it. In Sect. 2 I described a 'trundling block' model that is transientist; I also described a 'moving shadow' view that is similarly transientist. These are not philosophically interesting views (at least, so I suggest; to repeat a claim I made earlier I don't think that anyone has-or shouldseriously consider these positions). So then, a question: in what sense are transientism, permanentism and pastism philosophically substantive and interesting? For all that we've seen so far, transientism appears compatible with some deeply strange models that don't seem to raise especially interesting questions. Certainly, $I$ am not interested in exploring the consequences of transientism if it is consistent with so many baroque and uninteresting positions. In any case, and much more generally: it's well and good for it to be claimed that some question (or set of questions) is interesting and substantive-quite another to show it. We need the showing if Deasy's argument is to succeed.

Second, given Deasy's classification, there's a fairly intuitive sense in which the classificatory scheme that he offers generates misclassification. If we think generally about classificatory schemes, they are typically supposed to group together like theories. It seems (intuitively) obvious that Parmenedianism has much more in common with presentism (traditionally conceived) than it does growing block (again, traditionally conceived).

If we hold fixed my claim that existence is presence and that a 'block' of reality exists, then which of Deasy's transientism or pastism turns out to be true turns on whether or not Existence Monism is true: pastism is true if Existence Monism is false; transientism looks to be true, otherwise. That's an interesting question to pursue, to be sure, and is certainly philosophically substantive. But it does not seem to be a debate between positions that are distinct with regards their commitments 
qua theories of the nature of time. Since this is supposed to be a debate about time (or so I assume) so this looks like a misclassification.

Third, I offer an informal argument sketch (to be expanded upon), though it draws upon my last point. Because of the various alleged countermodels I suggested in Sect. 2, and the Parmenmedian model described a moment ago, it seems reasonably clear that the classification that Deasy offers is arbitrary. Arbitrary classifications do not generate philosophically substantive debates. That being so, Deasy's reclassification should be rejected. Unpacking this quick argument will take some space.

To get a feel for what I'm calling 'arbitrary classification', consider the responses to van Inwagen's (1990) special composition question (when does composition occur?), as they are ordinarily classified. We have:

Mereological nihilism: composition never occurs

Restricted composition: composition sometimes occurs

Mereological universalism: composition always occurs

So far, so good. But now imagine an obviously bad reclassification.

Mereological nihilism*: composition never occurs or occurs only in those cases where objects are fastened to one another.

Restricted composition*: composition sometimes occurs, but not when objects are fastened to one another

Mereological universalism: composition always occurs

So, we may ask: which of the views (Mereological nihilism*, Restricted composition* and mereological universalism) is true?

To repeat: I think that the re-classification that leads to this question is bad. Though note: the reclassification is certainly clear. The positions in the reclassification are certainly not compatible with one another. And, most salient for the current matter at hand, the reclassification enables us to ask questions that are by some measure interesting. It's certainly open which of the three views in the reclassification is true. Note, then, the parallel with Deasy's own attempted reclassification.

I do not think that a debate along these lines would be genuinely philosophically substantive. For, at least so far as I can tell, the carving up of positions that is generated by the revised classification is arbitrary; it lumps together views (in particular, the view that composition never occurs; the view that composition occurs but not when objects are fastened to one another) that do not resemble one another in respects that are salient to the question at hand. ${ }^{23}$ If someone wants to assert that Mereological nihilism* and Restricted composition* are philosophically substantive and interesting positions: well, there's not a lot that I can do to show, definitively, that they're wrong. Interest is in the eye of the beholder, after all, and perhaps substantivity comes along for the ride. But to the extent that the positions in the

\footnotetext{
${ }^{23}$ One way to put this would be to borrow from Sider (2011) and say that the positions do not "carve nature at the joints' in certain respects. I don't especially like that way of describing matters, but some do, and it may prove a useful heuristic and so I include it here.
} 
reclassification lump together views that appear fundamentally different from one another, the positions described in the reclassification do not seem to me to be philosophically substantive. I call this an arbitrary classification and describe as arbitrary any classification that groups together positions that appear fundamentally different from one another.

And although I do not wish to suggest for a moment that Deasy's reclassification of debates in the philosophy of time is on a par with the reclassification I've just described in the mereological case, the general point holds. The classification Deasy describes is arbitrary: the trundling block, moving shadow and the a nonparmenedian version of existence presentism, are not positions that seem to have anything substantive in common; not in respect of the philosophy of time. Any way of classifying positions in the philosophy of time that lumps these three models together is, I submit, arbitrary (in a fashion similar to that in which the reclassification in the mereological case is arbitrary). ${ }^{24}$ And yet all of these positions are transientist: thus, so much the worse for transientism. As in the mereological case, we should reject classifications that are arbitrary. Thus, we should reject Deasy's reclassification, and we should reject with it a preference for classifying views as either permanentist, transientist or pastist.

\subsection{Re-shaping the Debate, Not Positions}

Of course, this does raise a further question. I've suggested that existence presentism is perfectly viable; it gives a clear account of what it is to be present. I developed this line in response to the charge that no version of presentism is sufficiently clear on what is meant by 'is present', in response to what I took to be the central charge made by Deasy: that no version of presentism is adequate because no version of presentism can give such an account.

But on the revised interpretation of Deasy (and Williamson) that we're considering here, the charge isn't merely that existing accounts of positions like presentism are bad because they cannot give a satisfactory account of 'is present', but that Deasy's way of proceeding is good because it brings with it a range of theoretical virtues; he is providing us with a whole new way to shape the debate. And whilst I've argued that Deasy's way of proceeding in fact fails to preserve the virtues he claims for it, it's nonetheless an open question as to whether or not a position like mine should be at the centre of debates in the philosophy of time. It's the approach that Deasy is interested in, not merely the positions themselves. So, ok: let's set aside classifying positions as transientist, pastist or permanentist: how, then should we proceed? 'Existence Presentism vs the rest' is surely no way to proceed. It seems clear that Existence Presentism tells us nothing about how we should proceed in the philosophy of time.

I think that part of this argument is correct. 'Existence Presentism vs the rest' is no way to proceed. If what we are after is a clear sense of how we're to engage in the metaphysics of time we will need something rather better to guide our hands.

\footnotetext{
${ }^{24}$ Of course, they do have in common that they satisfy Deasy's definition of transientism. But to say that a classification is substantive because it is the very classification that it is, is obviously circular.
} 
And that means that, since I am rejecting Deasy's means of proceeding, and I am rejecting Correia and Rosencrantz's way of proceeding, it is incumbent upon me to say something rather more positive about how we should set about doing things. I cannot be purely destructive; I must also be positive.

So, how to proceed? What are the questions we should be asking? Well, Deasy (2017: 391) thinks that we should be asking (i) Do things begin to exist? (ii) Do things cease to exist? I've objected to the results of pursuing those questions. In contrast, then, since this is a debate about the metaphysics of time, I think that we should do metaphysics. And I think that engaging in the metaphysics of $\mathrm{x}$ (for all $\mathrm{x}$ ) requires two things of us. It requires us to ask existence questions ('what is there'?) and it requires us to ask kind questions ("of those things that exist, what kinds of entity are they?'). ${ }^{25}$ And I think that this is the way that the philosophy of time has proceeded.

That being so, I do not think that Deasy is correct when he states that the traditional questions in the minds of those who theories about time are: (i) are there past things? Are there future things? (2017: 378). I think that the traditional questions are-and have always been-what is there? And, how is it? (In the current context this second question amounts to "what is it to fall under the predicate is present'? What metaphysical kind is 'presence"?) In short: first we first ask our existence questions, then we ask our kind questions.

Presentists answer the existence question: only present things. Growing Block theorists answer: past things and present things. Eternalists answer: past, present and future things (and offer a reductive analysis of what it is to be past, present and future). ${ }^{26}$ Now to be sure, some (austere Quineans) may say that there is no further work to be done in answering the second question. But others may say more. For instance, a presentist may say that there is some property of presentness; perhaps it

\footnotetext{
25 Van Inwagen (2009: 4) identifies three questions for metaphysics, the first of which in fact contains two questions: 'What are the most general features of the world, and what sorts of thing does it contain?'. I see these as the same questions I would have us ask, in part because of the kinds of answer he sees as legitimate (without necessarily endorsing) in response: (e.g.) God exists, and what it is to be God is to be infinite, and a spirit (c.f. 2009: 5). Thus, we ask what there is (God) and we ask what God is like (infinite, and a spirit). Similarly, it's easy to see debates between realists about property as having that exact structure: first we argue that properties exist, then we try to work out what they are (tropes, platonic universals, Aristotelian universals, etc.). Similarly, those who think that we are committed to possible worlds can be viewed as proceeding in this fashion: first we establish a case for the existence of worlds, then we try to establish what kind of thing a world would be. Last, note that this way of proceeding is, I think, very similar to that taken by Schaffer (2009: 354) in his 'sorted' approach to metaphysics. That is: 'For any alleged entity, the sorted conception offers $n+1$ classificatory options for $n$ many categories: either the entity is in E1 or E2 or... or En, or else binned as non-existent.' Thus, either we describe the entity as existing, and hence must determine which category the entity is in (that is, what kind of entity it is), or else we must deny that the entity exists. Where Schaffer and I part ways is that he also argues that existence questions are (nearly always) trivial, such that the answer to existence question is (nearly always), 'yes'. See [author] for reasons to reject this approach. Thus, my approach to metaphysics in general (though perhaps not universally held) is far from revolutionary.

26 Merricks (2007: 125, fn 7) takes a similar position-that the difference between presentism and eternalism doesn't just come down to a disagreement as to which entities exist, but to the nature of what it is to exist at a time, and the nature of time itself.
} 
is a Platonic universal, that every object instantiates. ${ }^{27}$ Some, such as myself, (see especially my 2012), will demur; they will deny that there is any such property; existence is presence, they may say. Thus, in any case, given the point is intended to be methodological: we first answer the 'what is there?' question and then move to the 'what is it to be present?' question. ${ }^{28}$

I don't think that this way of characterising presentism (or the debate in general) is inappropriate. Markosian (2004) in his canonical defense of presentism first defines the view as 'only present objects exist', and then moves to characterise it further as follows:

According to Presentism, if we were to make an accurate list of all the things that exist...there would not be a single non-present object on the list. (2004:

So, there is our claim about what exists. He goes on:

...the same goes for any other putative object that lacks the property of being present. All such objects are unreal, according to presentism. (2004: 48-my italics)

And here is our claim about what it is to be F; what it is to be present is to instantiate a property of presence.

Thus, first: the only objects that exist are present objects. Second, presence is a property. We ask our existence question; we ask our kind question. ${ }^{29}$ (We could go on to ask what kind of property 'presence' would be-trope, universal, etc. No-one has explored this space, to date (so far as I know). I assume that the thought is that whatever we think about properties in general will port to what we think about the putative property of presence. Nonetheless, there is clearly logical space for

\footnotetext{
${ }^{27}$ I think it's possible to characterise Correia and Rosenkrantz (2015) as engaged in answering the first question as the presentist would (what exists? Only present things), but then answering the second without positing a property of presence; they need merely times. At least, that's one read of their project. As I noted in my criticism of their view, my criticism is of the outcome of their attempt to rescue presentism without using the locution 'is present', not the general approach. If they can define presentism in a purely logical way, making reference only to times, and not deploying the predicate 'is present', then that's all to the good. That would be a reductive analysis of presence, I think. Again, it is not their approach that I'm critical of, so much as the outcome of that approach.

${ }^{28}$ And we may then return to our first question. Putative answers to the kind question may lead us to revisit our answers to the existence question if (e.g.) the candidate kind is thought to be implausible. Thus, if one thought that there was a case for thinking that numbers exist, that case might be overturned if one thought that numbers would have to be abstracta, and that abstracta are implausible in some way.

29 Those who explicitly discuss what presence would be in presentism include, but are not limited to: Craig (1997), McKinnon (2013), Smith (2002), Tallant (2012, 2014), and Zimmerman (1996, 2008: 212). Merricks (2007: 125) offers the closely related analysis of 'existing at the present time' as 'existing', which will serve as analysis of 'being present' so long as 'existing at the present time' is read as equivalent to 'being present' - as sounds reasonable. I think that it's plausible to see both Correia and Rosencrantz (2015) and Rasmussen $(2012,2015)$ as offering reductive accounts of presence. To that extent, they can be seen as following in Crisp's (2007: 98, 102-5) shoes, where he looks to offer such a reductive analysis of the A-properties, including being present. Notably, Prosser's (2007) argument against versions of the A-theory, including presentism, explicitly trades upon the fact that presence would be a property, given presentism. That's a decent number of folks invested in the question of what it is to be present.
} 
arguments in the other direction: given presentism, if presentism is a property, what theory of properties is suggested?)

Similarly, recall the quote (above) from Briggs and Forbes (2017) that formed a part of their statement of the growing block view: 'Only past and present events exist, while future events do not. The present is thus the last time in existence.' We first answer the 'what is there?' question (only the past and present objects); we then answer the 'what is it to be past? What is to be present?' questions: being present is existing at the last time in existence; being past is existing without existing at the last time in existence. Again: first we answer our existence question, then we ask our kind question.

Now to be fair to Deasy, I do think that philosophers working in the philosophy of time have unduly focused their attention on the existence question. It is relatively unusual to see philosophers of time wondering about what it is to be present (for instance) given presentism — though Craig's (1997) 'Is Presentness a Property?' is a very obvious outlier and there are a range of others (cf. fn 29) invested in the project. It is far more usual to see debates about whether the presentist's ontological commitments (their answers to the existence question) are defensible. Nonetheless, we should not mistake a lack of focus for a lack of relevance. I see nothing revisionary about the traditional approach I suggest (though it is not the one that Deasy identifies) and, at least so far as I can see, it is perfectly reasonable.

In sum, then: up until this section I treated Deasy as arguing against, and replacing, existing definitions of presentism. I took that to be his principle aim. I argued that his arguments fail due to an internal inconsistency (and that we can also object to Correia and Rosencrantz's attempt to define presentism). In this section I have explored the possibility that Deasy is not focused on definitions of presentism, but is instead focused upon re-framing the debate in new terms-exact match with old positions be dammed. I've also argued that his arguments in favour of that reframing fail and at least suggested an existing framing to the debate (that is not one that Deasy identifies). Whether that ultimately proves to be viable is a different matter, but I think that it is the framing that has been used and that-at least prima facie-it is an approach perfectly consistent with our general approach to metaphysics. If all that we require is perspicuous definition of presentism, Existence Presentism will do. If we require a methodology for the metaphysics of time, we should adopt the one described. However we are to interpret Deasy, then, it seems that we have a viable response. In the face of all of which, presentism remains. ${ }^{30}$

\footnotetext{
${ }^{30}$ Lots of people helped with this paper. I'd like to thank all participants in Metaphysics of Spacetime conference, held at Alghero in 2016, where an early version of this paper saw the light of day. In particular, thanks to David Braddon-Mitchell, Cruz Davis, Matt Leonard and Kristie Miller for comments and criticisms. Later versions of the paper proved sufficiently unpopular to be rejected on several occasions; my thanks to the referees who gave useful feedback. I've done my best to respond to you. I'd also like to thank David Ingram and Daniel Deasy for very useful discussion about some of the key issues in the paper and two referees for Erkenntnis for some really helpful feedback.
} 
Open Access This article is distributed under the terms of the Creative Commons Attribution 4.0 International License (http://creativecommons.org/licenses/by/4.0/), which permits unrestricted use, distribution, and reproduction in any medium, provided you give appropriate credit to the original author(s) and the source, provide a link to the Creative Commons license, and indicate if changes were made.

\section{References}

Baron, S. (2014). The priority of the now. Pacific Philosophical Quarterly, 96, 325-348.

Bergman, M. (1999). (Serious) Actualism and (Serious) Presentism. Nous, 33, 118-132.

Bigelow, J. (1996). Presentism and properties. Philosophical Perspectives, 10, 35-52.

Briggs, R., \& Forbes, G. (2017). The growing-block: Just one thing after another. Philosophical Studies, 174(4), 927-943.

Cameron, R. (2015). The moving spotlight. Oxford: OUP.

Correia, F., \& Rosencrantz, S. (2015). Presentism without presentness. Thought, 4, 19-27.

Craig, W. L. (1997). Is presentness a property? American Philosophical Quarterly, 34, $27-40$.

Crisp, T. (2004a). On presentism and triviality. In D. Zimmerman (Ed.), Oxford studies in metaphysics, 1 (pp. 15-20). Oxford: OUP.

Crisp, T. (2004b). Reply to Ludlow. Oxford Studies in Metaphysics, I, 37-46.

Crisp, T. (2007). Presentism and the grounding objection. Nous, 41, 90-109.

Deasy, D. (2017). What is presentism? Nous. https://doi.org/10.1111/nous.12109.

Fiocco, M. (2007). Transient presentism. American Philosophical Quarterly, 44, 191-212.

Forbes, G. (2016). The growing block's past problems. Philosophical Studies, 173, 699-709.

Ludlow, P. (2004). Presentism, triviality, and the varieties of tensism. Oxford studies in metaphysics, I, 21-36.

Markosian, N. (2004). A defense of presentism. Oxford Studies in Metaphysics, 1, 47-82.

Markosian, N. (2010). Time. In E. N. Zalta (Ed.), The Stanford encyclopedia of philosophy (Winter 2010 Edition). http://plato.stanford.edu/archives/win2010/entries/time/.

McKinnon, N. (2013). Characterising presentism. In R. Ciuni, K. Miller, \& G. Torrengo (Eds.), New papers on the present (pp. 13-30). Munich: Philosophia Verlag.

Merricks, T. (2007). Truth and ontology. Oxford: OUP.

Meyer, U. (2005). The presentist's dilemma. Philosophical Studies, 122, 213-225.

Meyer, U. (2013). The triviality of presentism. In R. Ciuni, K. Miller, \& G. Torrengo (Eds.), New papers on the present (pp. 67-172). Munich: Philosophia Verlag.

Prosser, S. (2007). Could we experience the passage of time? Ratio, 20, 75-90.

Rasmussen, J. (2012). Presentists may say goodbye to A-properties. Analysis, 72, 270-276.

Rasmussen, J. (2015). Tenseless times. Philosophical Studies, 172, 3221-3227.

Savitt, S. F. (2006). Presentism and eternalism in perspective. In D. Dieks (Ed.), The ontology of spacetime (pp. 111-127). Amsterdam: Elsevier.

Schaffer, J. (2007). From Nihilism to Monism. Australasian Journal of Philosophy, 85, 175-191.

Schaffer, J. (2009). On what grounds what. In D. Chalmers, D. Manley, \& R. Wasserman (Eds.), Metametaphysics (pp. 347-383). OUP: Oxford.

Sider, T. (2006). Quantifiers and temporal ontology. Mind, 115, 75-97.

Sider, T. (2011). Writing the book of the world. Oxford: OUP.

Smart, J. (2008). The tenseless theory of time. In T. Sider, J. Hawthorne, D. W. Zimmerman (Eds)., Contemporary Debates in Metaphysics (pp. 226-238). Oxford: Blackwell.

Smith, Q. (2002). Degree presentism. In C. Callender (Ed.), Time, reality and experience (pp. 119-136). Cambridge: CUP.

Stoneham, T. (2009). Time and truth: The presentism and eternalism debate. Philosophy, 84, 201-218.

Tallant, J. (2012). (Existence) Presentism and the A-theory. Analysis, 72, 673-681.

Tallant, J. (2014). Defining existence presentism. Erkenntnis, 79, 479-501.

Tooley, M. (1997). Time, tense and causation. Oxford: Blackwell.

Torrengo, G. (2016). Presentism and the sceptical challenge. Manuscrito, 39, 101-116.

Van Inwagen, P. (1990). Material beings. Cornell: Ithaca.

Van Inwagen, P. (2008). McGinn on existence. Philosophical Quarterly, 58, 36-58.

Van Inwagen, P. (2009). Metaphysics (3rd ed.). Boulder: Westview Press. 
Williams, D. C. (1951). The myth of passage. Journal of Philosophy, 48, 457-472.

Williamson, T. (2013). Modal logic as metaphysics. Oxford: OUP.

Zimmerman, D. (1996). Persistence and presentism. Philosophical Papers, 25, 115-126.

Zimmerman, D. (2008). The privileged present: Defending an "A theory" of time. In T. Sider, J. Hawthorne, \& D. Zimmerman (Eds.), Contemporary debates in metaphysics (pp. 211-225). Oxford: Blackwell.

Zimmerman, D. (2011). Presentism and the space-time manifold. In C. Callender (Ed.), The oxford handbook of philosophy of time (pp. 163-244). Oxford: OUP. 